\title{
STEM Education in the United Arab Emirates: Challenges and Possibilities
}

\author{
Ghaddah Al Murshidi \\ United Arab Emirates University (UAEU) \\ United Arab Emirates (UAE)
}

\begin{abstract}
Science, Technology, Engineering and Mathematics (STEM) education has become a popular learning approach globally in the $21^{\text {st }}$ century. This is because the world is on the brink of a technological revolution which has its roots in these fields. The present study takes an in-depth look into the United Arab Emirates (UAE) economy as a model that has exemplified the drive towards innovation and a knowledgedriven economy to meet up with current realities. The present study was framed as a theoretical review to address the topic under consideration, relying on evidence from relevant literature. A total of 63 articles were reviewed and they include government reports, news publications, primary research studies, and theoretical analysis. These materials were utilized to comprehensively synthesize research on the current stance of STEM education in the UAE, as well as the challenges faced, and projected possibilities. Findings revealed that the UAE has made better progress but is limited by challenges such as lack of interest in STEM fields by UAE nationals and, the inaccessibility of STEM education across all age groups and income earners. In the face of opportunities such as the development of collaborative learning, a Gross Domestic Product (GDP) boost of at least 12\% and, the preparation of Emiratis for the future workplace, recommendations were made. This present study recommends that still there is need for intensification of effort on personal and professional development for teachers of STEM which will consequently affect the interest of students in STEM fields. Also, STEM education should be made accessible across all age groups and all citizens, regardless of their financial status. Further research should focus on expanding the scale of this research to include a participant pool in order to elicit responses and reflections from a group of students, schools, or instructors, using more in-depth qualitative research methods.
\end{abstract}

Keywords: STEM; United Arab Emirates; Artificial Intelligence; Fourth Industrial Revolution. 


\section{Introduction}

The United Arab Emirates is a federation of seven emirates: Abu Dhabi, Dubai, Sharjah, Ajman, Umm-al-Quwain, Ras al-Khaimah, al-Fujairah. This federation was created in 1971, nine years after oil was discovered and exported. Before the discovery of oil, the UAE economy was mostly dependent on fishing, seafaring, pearl extraction and trading, nomadic animal husbandry, and subsistence agriculture. These Emirates operated a pure subsistence economy with limited natural resources (Shihab, nd). Then came the discovery of oil, which catapulted the economy from a stage of lack to a stage of massive savings and capital accumulation necessary for economic development. Utilising these natural resources, the UAE boosted its social and economic infrastructure and attained economic growth within a short time. It joined OPEC and has since grown to be one of the most significant oil producers in the world. Since then, the growth of the UAE has been mostly dependent on the discovery, and efficient production of oil and gas products. Records show that it currently holds approximately $6 \%$ of the world's proved reserves and plans to increase crude oil productivity by 800,000 barrels per day to 3.5 million barrels per day in 2020. Sharing international gas pipelines with Qatar and Oman, the UAE exports natural gas. Hydrocarbon exports are also a source of significant revenue, and as of 2013, this revenue rose to a whopping $\$ 123$ billion (IMF, 2014).

Over the past three decades, oil prices have continued to drop, and the sharp decline in oil prices is a pointer to the fact that the oil sector is becoming saturated globally. Past episodes were in 1985-86, 1997-98, 1990-91, and 2008-09. The latest was in June 2014-January 2015, and since then, these prices have continued to dwindle. Empirical estimates reveal that supply is more than demand, and nations are working on alternative sources of energy such as nuclear power, solar power, ethanol, and wind power (Baffes et al., 2015). Cars are now powered by rechargeable batteries, and power can be generated for industrial purposes using alternatives that do not include fossil fuels. It implies that diversification of the UAE economy should be at the forefront of government plans to ensure global competitiveness. As opined by the US Energy Information Administration (2015), the UAE took a shortcut to economic development using revenue made from massive oil sales to fast track its growth. To ensure economic stability, diversification into non-oil sectors has become extremely important. The government has been making investments in nonenergy sectors such as real estate, tourism, trade and manufacturing, infrastructure, and technology in a bid to generate revenues to cushion the effects of the global oil price decline. But these are not enough as the world is embarking on a period of unparalleled technological advancement, which will present challenges and opportunities within the next 5 to 20 years (World Economic Forum Report, 2016).

Currently, the world is focused on technological innovations and high technological research and development; these have been projected to be the future and will become critical drivers of the economy (WEF, 2016). This current era referred to as the era of the fourth industrial revolution is billed to combine digital, physical, and biological knowledge in ways never seen before. As opined by WEF (2016), the fourth industrial revolution, usually called industry 4.0 or 
4IR can be referred to as the current and developing environmental transformation in the way humans function. This is as a result of disruptive technologies and trends such as robotics, internet (IoT), virtual reality, and artificial intelligence (AI). AI, which explores the ability of machines and computers to learn and act without being explicitly programmed is a field considered to be of great importance in today's world. The era of the fourth industrial revolution is one with focus on science and advanced technology. Therefore, global institutions of learning have shifted focus to training its scholars in areas such as science, technology, engineering and mathematics (STEM) to better prepare for the technological driven industrial revolution that is already upon us. Schilero (2013, p. 48) argues that;

"Knowledge economies, unlike economies that depend on finite natural resources, rely on the potentially limitless creativity and talents of its people to generate economic value. Constructing a knowledge-driven economy requires new skills, new ideas and a high level of creativity from a high-trained, flexible and adaptable workforce" (Schilero, 2013).

Emphasis is on "knowledge economies" because for nations with the right knowledge and skills, digitalisation and globalisation will be liberating, but those who are unprepared will face a vulnerable and insecure life without prospects. Sengupta (2019, p. 1) citing Brett Griven, posits that "as we move further towards a knowledge-based economy, a large majority of jobs will be linked to careers focused on science, technology, engineering and Mathematics (STEM) (Sengupta, 2019, p. 1). This implies that STEM education should be the focus of institutions of learning from the grassroots. Children should be engaged with STEM education as early as kindergarten to pique their interest early on and expose them to the world currently on the brink of technological revolution. Several studies have evaluated the progress of STEM education in the United States, United Kingdom, other European countries, Asia, Africa, and the Middle East. In the UAE, Soomro (2019) creates awareness for STEM-based education, detailing its needs and proposing an implementation framework. Makhmasi, Zaki, Barade, \& Al- Hammadi (2012) focused on the interest of grade 9 to 12 UAE students in STEM fields, while Varughese \& Varughese (2018) also conducted a similar study but with focus on schools in Dubai. Due to the dearth of research on the challenges and possibilities of STEM education in the UAE, this paper conducts an in-depth research and presents significant findings on the subject matter.

To this end, this paper is divided into two parts. The first part will conceptualise STEM education and provide a vivid discussion on the current state of STEM education in the UAE. The second part sets out to reveal the importance of STEM education to the UAE, and expose the challenges currently faced by the UAE in its bid to prioritise STEM education and successfully integrate it into its school system.

\section{Conceptualisations of STEM Education}

STEM is an acronym for Science Technology, Engineering, and Mathematics. Previously referred to as Science, Mathematics, Engineering, and Technology (SMET), STEM education is an initiative introduced to empower students with 
the requisite skills needed to make them creative problem solvers, and to create good transition along their career path (White, 2014). There is no single definition for STEM, and according to Xie et al., (2015), it is commonly used to reference a set of educational and occupational fields related to science. STEM education is thus the purposeful integration of these disciplines (Science, Technology, Engineering, and Mathematics) in solving real-world problems. Capraro (2014) maintained that STEM is a teaching composite of any two or more fields of science, technology engineering, and mathematics which might occur as a result of duplicity of real-life and problem-based learning. Wise Lindeman and McKendry (2015) went a notch further by defining STEM education other than it being a composite of four subjects, it is also a teaching method based on constructivism and constructionism. STEM was also defined by Park et al., (2016), Glancy and Moore (2013), Mitts (2016), Asghar et al., (2012), Brown et al., (2011), to reveal it's integrative and multidimensionality. They maintained that STEM education is a composite of sciences, mathematics, engineering, and technology into a cross-disciplined curriculum, which is predicated on strategies and problem-solving skills for solving problems. The ability to solve real-life problems is a crucial attribute of STEM education, and it was noted by scholars to allow students explore, test, and proffer solutions to problems in real context that will force critical thinking (Kennedy \& Odell 2014; Asghar et al., 2012).

STEM education is essential globally, and it aims at providing well-qualified graduates (Mcdonalds, 2016), which in the long run will influence the country by providing necessary workforce vital for handling the needs of the country (Wan-Husin et al., 2016). There is a changing shift in educational paradigms globally, and the shift is towards STEM education. What necessitated the drive for STEM education is to ensure a multidisciplinary approach to issues wherein there is application of science, technology, engineering and mathematics to tackle current challenges and solve real-life problems (Chalmers et al., 2017). In STEM education, there is a combination of many disciplines which has a primary aim of having an integrative approach to issues. What makes STEM education unique is its novelty and its ability to solve real-world issues in different sectors such as energy, health, environment etc. (Durik, Hulleman \& Harackiewicz, 2015; Kennedy \& Odell, 2014).

To critically analyse STEM education, there are two approaches. They include the integrative approach, which is a composite of major disciplines integrated into one, and the multidisciplinary approach, which integrates knowledge from several disciplines. These approaches can be achieved by using strategies of problem-based learning, project-based learning or inquiry-based learning (Mitts 2016; Bruce-Davis et. al., 2014; Asghar et. al., 2012). To ensure that the ideals of STEM education is realized, there is a need to bridge the gap between discipline and ensure that there is a multidisciplinary approach to all pedagogical apparatus (Asghar et al., 2012). Winn, Choi and Hand (2016) highlighted the complexity of STEM education by maintaining that STEM education is a broad field of study in that the disciplines embedded in it are multifaceted and has many dimensions, which gives an aesthetic and challenging feel to it. With scientific inquiry and engineering design at the core of STEM education, it can 
facilitate better achievement which can be utilized in creating faster problemsolving abilities (Hansen \& Gonzalez 2014). With the need to have developed economies, STEM education has been proven as a veritable panacea to economic challenges. In the works of Ritz and Fan (2015), it was reported that STEM education is responsive to economic challenges globally especially in the developed world because it is geared towards having the necessary skills that is needed in the current dispensation. The pragmatic attribute of STEM education was revealed by Moye, Drugger \& Starkweather (2014) who opined that STEM education supersede learning its constituents. It goes forward to practically apply the disciplines, theories, designs and laws in a way that shows the utilisation of knowledge which also allows students the opportunity to think across several disciplines.

With a constant drive towards change in the general parlance, energy challenges, general economic meltdown, technological innovation and evolution, recent climate change issues, there is a need to come up with new educative ways to cope with these challenges now and in the future. STEM education presents itself as a significant panacea to these issues. The teaching of sciences, mathematics, engineering and technology will strengthen educational content and be more tailored towards solving real-life issues. Therefore, there is a need to have a new generation that is well loaded with the requisite skills that can tackle these current and future realities and also impact the society by raising the economic stance of the country (Radloff \& Guzey, 2016; Shernoff et al., 2017).

\section{Imperative of STEM Education in Achieving UAE's National Goals}

Education is an essential factor for ensuring enhanced human capital and it is also a significant tool for economic growth in the United Arabs Emirates (Schultz, 1960: Becker, 1962). The educational system is pivotal to the knowledge economy since it creates rooms for inculcation of positive attitudes which makes change possible and increases learning. With STEM education, there will be a promotion of higher education in some courses that applies to engineering and applied sciences which can ensure the development of new technologies favourable to the achievement of the national goals of United Arab Emirates. With STEM education being a panacea to providing economic growth and development now and in the future, it is plausible to examine some of the areas where it offers some possibilities in realizing the goals of United Arab Emirates as a federation that is innovative and self-sufficient. Human capital is vital for all processes of innovation, and having a well-educated population saddled with the skills needed for performance in their career will ensure that the necessity for innovation is achieved. With STEM education, there will be massive turn out of graduates that will be able to fit in across national and international careers in the global sphere (Hathcock et al., 2015). With the United Arab Emirates drive for self-sustainability, having graduates in STEM discipline will contribute more to the federation achieving its goals.

Bilgin, Karakuyu and Ay (2015) believed that students were fascinated towards science when project-based learning was used. Creativity in people makes them adventurous, searching for solutions to the challenges of the federation, which will in the long run result in achieving the goals of the nation. Also, findings 
from the work of El Sayary (2014) showed that students in UAE that were taught using STEM project-based learning had better $21^{\text {st }}$-century skills. These skills include cognitive, content and collaborative skills, which are vital towards achieving United Arab Emirates' national goals. This is in line with the definition of the prime minister of UAE (Moonesar, 2015) who stated that the aspiration of individuals, private institutions and governments to achieve development by generating creative ideas and having new products, services and operations that have positive bearing on the overall quality of life.

Also, in the works of Powell and Snellman (2004), it was revealed that an economy seeking to be knowledge-based must be scientifically and technologically driven, and there must be reliance on intellectual dexterity other than natural resources, which can only be achieved by relying on STEM education. With science and technology being a key component of STEM discipline, they are critical drivers of a knowledge-based economy keen to the realisation of national goals in the United Arab Emirates. This is in line with the UAE'S vision 2021 which opines that productivity and competitiveness are driven by investment in science, technology, research and development which can only be ensured by prioritising investment in STEM education.

Demands for new industries in UAE is on the increase, and research revealed that about 60,000 engineers would be needed between 2011 and 2020 according to the UAE society of engineers, and efforts must be made to encourage young people to go into STEM education to leverage on these opportunities that comes with the demands. Also, The Abu Dhabi Economic Vision 2030, a framework for economic development, will create massive demand for home-grown scientists, technologists and engineers hence the imperative of STEM education in achieving the national goals in the United Arab Emirates. This is in line with the findings of the World Economic Forum (2016) which reported that STEM literacy is a pointer to the future readiness of countries.

There is a general recognition that skills and human capital is the crux of economic prosperity and social wellbeing in the $21^{\text {st }}$ century and these skills can only be imparted through STEM education. This typifies the importance of STEM education in building a sustainable workforce that will be able to compete globally and provide solutions to the challenges plaguing United Arab Emirates. With UAE'S vision 2021 in view, innovation, research, science and technology will be the drivers of a knowledge-based productive environment, and this can only be made possible by STEM education. With the integrative, pragmatic and multidisciplinary feature of STEM education, it has the potency to ensure that the national goals of UAE are achieved.

\section{STEM Education in the United Arab Emirates (UAE): Contemporary Strides}

It is established that there exists a positive relationship between education and economic growth as education is a critical element in developing the necessary skill levels for growth and modernisation (Shihab, nd.). Educationally, the United Arab Emirates is a developing nation with a rapidly growing economy, which is currently placing premium on quality education for its citizens which 
will consequently impact the students and the economy at large. The UAE operates public and private sector schools, military schools, higher education, and vocational training establishments. Primary school education is compulsory for all citizens, and citizens can choose to undergo higher education in the UAE or abroad through a generous scholarship system. As of 2018, 20\% of the government's total budget was allocated to general, higher, and university education programs. The prioritisation of the education sector in the UAE is shown in the current strategic plan for 2017-2021 that seeks to raise an already high rate of upper-secondary graduation rate, which was $96.7 \%$ in 2016, to $98 \%$ in 2021(Kamal,2018). According to a 2018 report by the Boston Consulting Group, the UAE's education market is expected to grow from $\$ 4.4$ billion in 2017 to $\$ 7.1$ billion by 2023 (Abbas, 2019). This campaign for a reformed education system is expected to start with Abu Dhabi, then Dubai and the other Northern Emirates have its focus on integrating creativity and innovative thinking into the school curricular (Shaer, Zakzak \& Shibl, 2019). The UAE is already doing enough for its citizens in the education sector, but the coming of the $21^{\text {st }}$ century with all its technological advancements exposed some loopholes. For one, the higher education institutions in the UAE are focused on training its citizens in areas such as business administration, health sciences, aviation technology engineering, information systems, and accounting systems. According to a popular estimate reported by the world economic forum, $65 \%$ of children entering primary school now will ultimately work in a job that doesn't exist today (WEF, 2016). It implies that education in the UAE must, therefore, be prepared to change with technology and its students trained to imbibe the skills needed for the future. It demands a proliferation of new, non-traditional options that STEM education offers.

STEM education came to the fore in UAE after 2010, when many educational outfits adopted the Next generation science standards (NGSS) as their science curriculum, which shows the novelty of STEM education in UAE and the Arabic region in general. As postulated by Shaer et al., (2019), Vision 2021 was announced in 2010 with education as one of its primary focus. This vision for education aims at training UAE students to be one of the best in reading, mathematics, science, and Arabic skills. This vision was adopted by the UAE to prioritise innovation as key for the development of a diversified economy. As opined by Dhuha Fadhel, "the UAE Vision 2021 states that the federal government will work on replacing the current investment-led growth strategy by a strategy that is driven by knowledge, innovation, research, science, and technology." (The Economist Intelligent Unit, 2014). To measure up with this change in economic direction, thousands of Emirati STEM graduates are needed, especially since the government strategy is focused on building an economy reliant on Emirati nationals. The UAE Society of Engineers announced that at least 60,000 extra engineers will be needed between 2011 and 2020, a feat that can only be achieved through STEM integration. Aligning with Vision 2021, the ministry of education came up with Strategy 2017-2021 to support the vision of promoting the fields of science, innovation, and technology in the UAE. Current student visa data show that of the $90.6 \%$ male students in the UAE, $74.2 \%$ study at the undergraduate level, with $45 \%$ of students enrolled in STEM fields. UAE's Programme for International Student Assessment (PISA) rankings 2012-2015 
improved for Mathematics, and the TIMSS results showed significant improvement for Dubai\& Abu Dhabi in mathematics and science in 2011-2015. It shows an improvement already in the performance of UAE students in the field of STEM. The goal of the government is to be among the top 20 highest performing countries in PISA and the top 15 highest performing countries in TIMSS (PWC, 2019; Kamal, 2018; The Economist Intelligent Unit, 2014).

According to a report by Shaer et al., (2019) for the Mohammed Bin Rashid School of Government (MBRSG), the government of the UAE has pushed STEM through education reforms through some strategic measures. After launching the UAE National Innovation Strategy in 2015, the government launched the Fourth Industrial Revolution in September 2017. The strategy involves a focus on innovation education and research in advanced sciences and artificial intelligence. The Artificial Intelligence strategy was also launched in 2017 with H.E. Omar Al Olama appointed a minister of Artificial Intelligence, the first-ever in the world. The government of the UAE also launched a council to oversee the implementations of the National Advanced Sciences Agenda 2031 and the Advanced Sciences Strategy 202. The National Science, Technology and Innovation Festival (NSTIF) is also held annually, and in January 2019, the Artificial Intelligence Robotics Series (AIR) was held. Also, an annual youthfocused program called "Think Science" has been running since 2012. Sometime in April 2019, the government of the UAE collaborated with the World Economic Forum (WEF) to inaugurate the centre for Fourth industrial Revolution in Dubai. This centre, fifth of its kind in the world after the United States, Japan, India, and China, is part of the plans of the government of the UAE to prepare its citizens for the future. The first batch of graduates from this centre were celebrated in September 2019.

All these are strategic programs encouraged by the government of the UAE through its Ministry of Education to attract students to the field of STEM so that STEM education in the UAE will be fully developed (PWC, 2019; Shaer et al., 2019). With the support of the government also, other bodies in the UAE are undertaking several measures to drive the integration of STEM education in the education system of the UAE. Late October 2019, the first Global DXB challenge was held in Dubai. It is a global gathering of creative young minds in the field of robotics and artificial intelligence (Gulf News, 2019). These efforts by the government of the UAE are still inceptive, recording improvements in developing STEM education in the UAE, but some challenges have continued to hamper the full integration of STEM education in the UAE.

\section{Methodology}

This paper explores the challenges and possibilities of science, technology, engineering, and mathematics education in the United Arab Emirates. A qualitative desk research was used in this study. A qualitative research approach is geared towards generating every tiny piece of data about a phenomenon. A systematic literature review was therefore carried out to comprehensively synthesize research on the current stance of STEM education in the UAE, as well as the challenges faced, and projected possibilities. This review sought to gain insights into the progress already recorded following the UAE's adoption of 
several STEM education policies, and how their application has affected its education system.

Using a qualitative desk research approach, 63 articles were utilised. 53 were published between 2014 and 2019, and 8 between 2004 and 2013. The other two were published in 1960 and 1962 respectively, and were cited for definitive purposes. These articles include government reports, news publications, primary research studies, theoretical analysis, and commentary on the STEM subject and its progress in the UAE. Qualitative and quantitative information obtained from these materials were used to describe the challenges and explore the possibilities of STEM education in the UAE.

\section{Findings and Discussion}

Reviewing relevant information from the collected articles, the findings of this study are discussed using two categories:

1. Challenges facing STEM education in the UAE

2. Opportunities of STEM education in the UAE

\section{Challenges Facing STEM Education in the UAE}

Speaking at a workshop in the UAE, the General Manager of Atlab, Senthil Kugan revealed that "the major challenge of implementing STEM is that the resources and the model which can be integrated to work with the schools and their respective curriculums should be in place" (Edarabia, 2015, p. 1). The implication is that all factors that will support the successful integration of STEM in the education system of the UAE must be present, and structurally balanced before the desired results can be recorded. One of this vital factors is the interest of the learners in STEM subjects. As stated by Laforce et al., (2017), "interest as a motivational construct refers to the state of being engaged or being likely to reengage with a particular object, event, or idea." Lack of interest in STEM fields is a significant challenge of STEM education in the UAE and, more arts graduates are churned out of higher institutions. Most students just want to achieve higher grades, and they are turned off STEM subjects because these subjects are perceived to be complicated. They prefer to take art subjects, or undertake majors they are sure they will excel and obtain high scores from (Shaer et al., 2019). Some students are influenced by their peers who negatively stereotype STEM as "unattractive." In contrast, others are influenced by the media who continuously reinforces the perception that STEM fields of study are only for the academic elites, which is not the case. Some classrooms are not equipped with modern technological resources that enhance and ensure ease of learning these STEM subjects. This makes learning uninteresting and less fun.

Shaer et al., (2019) further state that there is a dearth of STEM resources in the Arabic language, and it is common knowledge that English is the global language of science and technology. Some UAE students are not very good with the English language, and this also affects their interest in the field of STEM. Good teaching of STEM subjects by 'capable' teachers will inspire learners and pique their interest in STEM subjects. This is another challenge of STEM education in the UAE; the unavailability of capable teachers, especially in public 
institutions. As opined by Makhmasi et al., (2012, p. 2), "teachers' capability can be defined as his/her role and personality in approach to delivering the academic curriculum." They insist that the relationship between the teacher and the learner, affects the interest of the learner in the field of STEM. Although they have obtained degrees and certifications and have had pre-service training, most teachers do not have the requisite training to handle STEM portfolios. They lack professional development to handle classrooms on STEM methods and tools (Shaer et al., 2019). Significant hindrances to teacher training are availability of resources and availability of time. Most times, the problem emanates from the enormous workload they have to handle as some teachers have to work 50 to 70 hours a week. They also have to spend time to prepare for classes and draft lesson plans, grade tests, and other assessment exercises, and also carry out other administrative duties. A lack of formalised training in the teaching methods and tools of STEM education has continued to hamper their deliverables (Shaer et al., 2019; Makhmasi et al., 2012).

Lack of training on the part of the teacher, also affects their translations of the objectives of STEM in their lesson plans. Aligning the objectives of STEM with lesson plans is of great importance; it requires the teacher to be familiar with the concepts and methods of STEM. Due to these challenges facing teachers in the UAE, they adopt the practice of using old lesson and activity plans, thus making it challenging to deliver a STEM integrated curriculum. Integrating STEM into the curriculum has also been reported to be difficult and challenging. Some school departments still find it challenging to translate curricular integration into lesson plans that can easily be delivered and understood by students in the UAE (Shaer et al., 2019). The integration of the curriculum is usually not well defined, and is dependent on individual teacher's capacity, knowledge, and creativity. This should not be the case as positive results will not be recorded until curriculum integration of STEM education is standardised. As stated by Edarabia (2015), a STEM class is one that finds a real-world problem and focuses on getting a solution. Designing a solution will involve building models and simulating situations, and these are what a STEM lesson should inspire. A teacher who has not adequately been trained on these models and methods cannot effectively imbibe such a lesson in a learner.

In the forefront of challenges faced by STEM education in the UAE is the high cost of STEM education. As stated by Pennington (2017), the cost of education has risen steadily in the UAE, especially with the increase in private schools who offer more learning choices. A report by HSBC also supports this claim revealing its damaging effect on STEM education in the UAE. This report show that students who intend to undergo a two-year post-graduate degree in the field of engineering are expected to pay tuition fees to the tune of $\$ 26,400$ in the UAE. In Dubai for example, as of 2019, the school fees ranged from $\$ 3,463.84$ to $\$ 17,449.32$ per annum for private school. This cost does not include projections for transportation, uniforms and books. This report further reveals that the school fees in the UAE is the second highest in the world (Maceda, 2017). This implication of high costs of tuition fees is that STEM education is not accessible to average UAE citizens who cannot afford it, and therefore, STEM education in the UAE is not for all citizens of the UAE. In June 2018, the Dubai Executive 
Council ruled that private schools in Dubai will not increase their fees for the 2018-2019 academic sessions (Edarabia, 2019). This is a commendable action but, more work needs to be done to ensure that education and most importantly, STEM education, is available to all Emiratis at all levels.

Recently, a group of education stakeholders in Al Barsha did not just express dissatisfaction about the exorbitant and high tuition fees it takes to deliver quality STEM, artificial and robotics education. They also lamented about the inaccessibility of STEM education to all students across all age groups (Gokulan, 2019). The curriculum should feature STEM subjects at both higher and lower levels of education, because it is vital that children are introduced to the field of STEM in their early years. Introducing STEM to kids will encourage creativity\& critical thinking; it will also develop their passion for STEM fields and, more students in the UAE will be interested in pursuing a STEM major. Lastly, there has been a reverse gender gap leading to the challenge of imbalance in STEM workplaces. The UAE now ranks relatively favourably in terms of gender equality, and female participation has improved. Women now outnumber men in secondary school at a ratio of 6: 4 and, between 2012 to 2014, the percentage of tertiary enrolments by the women shot up from $42 \%$ to $58 \%$. In the United Arab Emirates University (UAEU) for example, the percentage of students rose from $38 \%$ in 1977 to $82 \%$ in 2016(Kamal, 2018). Women now outnumber men in STEM disciplines, and a recent report by The National (2018) reveals that $77 \%$ of students taking computer science classes are female, and $44.5 \%$ female participation in engineering. The challenge in this 'supposed improvement' is that the increase of women undertaking STEM majors is not translating to a rise of women in STEM workplaces post-education. This is due to variety of reasons such as the social stigma associated with STEM careers, the double-bundle syndrome that implies that women are only good for family and childbearing and, the gender bias faced by women in STEM workplaces(Kaul, 2016; Kamal, 2018). Women should be encouraged so that their representation in the STEM workforce will improve all across the UAE.

\section{Opportunities of STEM Education in the UAE}

In the UAE today, remarkable attention is being paid to the field of STEM, enhancing the quality of teaching and learning, and also broadening institutional participation and capacity for handling STEM subjects. There is currently increased attention in the quality of education delivered across the UAE, with strategies in the pipeline on how to improve it. The opportunities of STEM education in the UAE are numerous, but the preparation for future jobs and employees using strategies in advanced technologies and artificial intelligence tops the list. The world economic forum states that $65 \%$ of children entering school today will work at jobs that do not currently exist. The 2018 future jobs report states that 75 million jobs could be displaced by 2022 , but new technologies will create 133million new jobs for people trained to work with machines and data (WEF, 2018). Fisk (2017) posits that twelve disruptive technologies reshaping the world in the era of the fourth industrial revolution. These include, renewable energy, advanced materials, 3D printing, energy storage, genomics, advanced oil and gas exploration, Internet of Things (IoT), cloud, advanced robotics and, autonomous vehicles. 
The government of the UAE has introduced the fourth industrial revolution and artificial intelligence strategy, which will yield technological innovations that will improve business efficiency and foster a smarter knowledge-based economy. The key fields of this strategy are innovative education, artificial intelligence, intelligent genomic medicine and, robotic healthcare (Hamidi, 2018; UAE Government, 2017). Bearing in mind that these are fields that will rule the future, UAE nationals are therefore preparing themselves to occupy future workplaces. In April 2019, the government of the UAE in cooperation with the World Economic Forum (WEF) inaugurated the centre for Fourth Industrial Revolution in Dubai. This centre, fifth of its kind in the world after the United States, Japan, India, and China, is part of the plans of the government of the UAE to prepare its citizens for the future. The first batch of graduates from this centre were celebrated in September 2019 and, charged to share their knowledge and expertise to all around them. This creates another opportunity in mentorship (Badam, 2019; Government of Dubai, 2019; WAM, 2019).

The integration of STEM education in the UAE also offers a valuable opportunity to increase Emirati models and mentors in the field of STEM. A study by Makhmasi et al., (2012) reveals that non-STEM students admitted to the fact that role models can play a crucial role in their choice of a major. This implies that increasing the dominance of STEM fields amongst students will also require the influence of mentors and models in these fields. Raising female mentors is also important as a study suggests that the growth of the GDP in the UAE can be boosted by $12 \%$ if more women participate in STEM fields (GE Hewar, 2018). Mentors can also be foreigners since there has been an influx of expatriates into the UAE who make up the majority of the population. According to a report published in October 2019, statistics show that the expatriate community makes up for about $80 \%$ of the population in the UAE (Global Media Insights, 2019). This is advantageous as there are skilled professionals in this mix who can mentor Emirati nationals.

Making the UAE a global hub for STEM and artificial intelligence will also create an opportunity for the development of collaborative learning with global institutions and professionals. Making the UAE a central hub for technological innovations has been an open invitation to highly skilled professionals to the UAE. These expatriates will collaborate with UAE nationals, sharing knowledge and experience in the field of STEM. It inadvertently offers an opportunity for expansion as knowledge sharing and collaboration will yield positive results in STEM fields and workplaces.

\section{Conclusion and Recommendation}

The complete integration of Science, Technology, Engineering, and Mathematics (STEM) education in the educational system of the UAE has become critical. This is because the world is practically on the brink of a technological revolution that will alter the way we live, work and, relate to one another. Artificial intelligence is all around us, from self-driving cars and drones, to virtual assistants and software that can translate and make investment decisions. The government of the UAE has continuously taken different measures to prepare UAE nationals for this future of advanced technology by supporting STEM fields through its 
Vision 2021, Vision 2030, the fourth industrial revolution, and artificial intelligence strategy amongst others. These efforts are still inceptive and have recorded some improvement in developing STEM education in the UAE. Still, challenges faced include, lack of interest in STEM fields by Emirati students and, lack of capable teachers to handle STEM portfolios. The dearth of STEM resources in the Arabic language is also a limitation as it is common knowledge, that English is the global language of science and technology. Other challenges hampering the full integration of STEM education in the UAE include the high cost of STEM education and the inaccessibility of STEM education to students across all age groups. Topping the list of the possibilities of STEM education in the UAE is its preparation for future jobs an employees using advanced technologies and artificial intelligence. Inaugurating a centre for the fourth industrial revolution in Dubai, the UAE became the fifth nation to adopt this strategy following countries like the United States, Japan, India, and China. A centre like this is projected to promote the image of the UAE as a global hub for STEM fields, thereby attracting highly skilled professionals in these fields into the UAE. This will increase Emirati models and mentors in the field of STEM as they play a key role in influencing non-STEM students to undertake STEM majors.

To this end, this paper recommends some solutions, with the first being that, more awareness should be created for the field of STEM to pique the interest of students. Nationals should be made to understand that it is not a field for the elites, but rather, a field that will determine the quality of life of every citizen soon. Creating a passion for STEM fields in young minds in their very early years will also influence their decision to undertake majors in STEM fields. STEM workplaces should be designed to support female employees, and employers should be made aware of the economic benefits. STEM education resources should be made available to all students who indicate interest regardless of their financial power. It implies that the cost of STEM education in the UAE should be regulated such that it is accessible to all. Finally, students should be encouraged to master the English language, and capable teachers should be trained specifically to handle classrooms on STEM methods and tools.

Limitations exist in this study. First, the findings of this research could be applied to other countries in the Gulf region, but are unlikely to have relevant specific implications outside these areas based on cultural differences. Secondly, the scale of this research is limited to data generated from other research sources. The absence of a participant pool of either a group of students, schools, or instructors directly involved in the progress of STEM education in the UAE is a limitation as personal experiences on the subject matter were not sampled. Future studies should consider an approach directly based on the experiences of these groups of people, as well as more in-depth qualitative methods to elicit responses and reflections. 


\section{References}

Abbas, W. (2019). Despite Oversupply, UAE Education Sector Offers Opportunities. Khalej Times, Local Business. Retrieved from: https://www.khaleejtimes.com/business/local/despite-oversupply-uaeeducation-sector-offers-opportunities. doi:10.4018/978-1-4666-1984-5.ch011

Asghar, A., Ellington, R., Rice, E., Johnson, F., \& Prime, G. (2012). Supporting STEM Education in Secondary Science Contexts. Interdisciplinary Journal of Problem-Based Learning, 6(2), 85-125. doi:10.7771/1541-5015.1349

Badam, R. T. (2019). WEF launches Dubai Centre for the Fourth Industrial Revolution. The National UAE. Accessed on October 28, 2019. Retrieved from: https://www.thenational.ae/uae/wef-launches-dubai-centre-for-the-fourthindustrial-revolution-1.854715

Baffes, J., Kose, M. A., Ohnsorge, F., \& Stocker, M. (2015). The Great Plunge in Oil Prices: Causes, Consequences and Policy Responses. Washington, DC: World Bank Group Policy Research Note. doi:10.2139/ssrn.2624398

Becker, G. (1962). Investing in Human Capital: A Theoretical Analysis. Journal of Political Economy, 70(5), 9-49. doi:10.1017/cbo9780511585982.009.

Bilgin, I., Karakuyu, Y., \& Ay, Y. (2015). The Effects of Project-Based Learning on Undergraduate Students' Achievement and Self- Efficacy Beliefs Towards Science Teaching. Eurasia Journal of Mathematics, Science and Technology Education, 11(3), 469-477. doi:10.12973/eurasia.2014.1015a

Brown, R., Brown, J., Reardon, K., \& Merrill, K. (2011). Understanding STEM: Current Perceptions. Technology and Engineering Teacher, 70(6), 5-9.

Bruce-Davis, M., Gubbins, E., Gilson, C., Villanueva, M., Foreman, J., \& Rubenstein, L. (2014). STEM High School Administrators', Teachers', and Students' Perceptions of Curricular and Instructional Strategies and Practices. Journal of Advanced Academics, 25(3), 272-306. doi:10.1177/1932202×14527952

Capraro, M., \& Nite, S. (2014). STEM Integration in Mathematics Standards. Middle Grades Research Journal, 9(3), 1-10.

Capraro, R., Capraro, M., \& Morgan, J. (2014). STEM Project-Based Learning. 2nd ed. Rotterdam: Sense Publishers. doi:10.1007/978-94-6209-143-6

Chalmers, C., Carter, M., Cooper, T. \& Nason, R. (2017). Implementing “Big Ideas" to Advance the Teacher and Learning of Science, Technology, Engineering and Mathematics (STEM). International Journal of Science and Mathematics Education, 15(1), 25-43. doi:10.1007/s10763-017-9799-1

Durik, A. M., Hulleman, C. S., \& Harackiewics, J. M. (2015). One Size Fits Some: Instructional Enhancements to Promote Interest. Interest in Mathematics and Science Learning, 1(1), 49-62. doi:10.3102/978-0-935302-42-4_3

Edarabia. (2015). Two UAE Public Schools to Introduce STEM Classrooms. Accessed on the 20 October 2019. Retrieved from: https://www.edarabia.com/104763/twouae-public-schools-to-introduce-stem-classrooms/

Edarabia. (2019). Dubai School Fees by Grade 2019. Accessed on the 20 October. Retrieved from: https://www.edarabia.com/dubai-school-fees/

El Sayary, A. M. A. (2014). The Effectiveness of Problem-Based Learning Strategy in STEM Education for Enhancing Students' 21st Century Skills. Dubai: The British University in Dubai (BUID) Digital Repository.

Fisk, P. (2017). The Fourth Industrial Revolution... How 12 Disruptive Technologies will Reshape Our World... and Their Opportunities for Your Business. Retrieved on the $20 \quad$ October 2019 from: https:// www.thegeniusworks.com/2017/07/disruptive-technologies-exactlyapplications-mean-business/

GE Hewar Blog (2018). One Mentorship at a time: GE Helps UAE Increase Female Professionals in STEM Fields. Accessed August 21, 2019. Retrieved from: 
http:/ / middleeast.geblogs.com/en/lang-en/one-mentorship-at-a-time-ge-helpsuae-increase-female-professionals-in-stem-fields/

Glancy, A., \& Moore, T. (2013). Theoretical Foundations for Effective STEM Learning Environments. Purdue University School of Engineering Education Working Paper https://docs.lib.purdue.edu/cgi/viewcontent.cgi?article=1000\&context=enewp

Global Media Insights. (2019). United Arab Emirates Population Statistics, 2019. Accessed 29 2019 October, Retrieved from https://www.globalmediainsight.com/blog/uae-population-statistics/

Gokulan, D. (2019). Pricey STEM Education Not Good Enough. Accessed 29th October 2019. Retrieved from: https://www.khaleejtimes.com/news/education/priceystem-education-not-good-enough

Government of Dubai, (2019). Mohammed Bin Rashid Attends Graduation Of $1^{\text {st }}$ Batch Of Fourth Industrial Revolution Programme. Media Office, Published $30^{\text {th }}$ September, 2019. Retrieved from: https://www.mediaoffice.ae/en/mediacenter/news/30/9/2019/mohammed-bin-rashid-attends-graduation-of-1stbatch-of-fourth-industrial-revolution-programme.aspx

Gulf News. (2019). Global Robotics Challenge Kicks Off in Dubai. Accessed October 24, 2019. Retrieved from: https://gulfnews.com/uae/global-robotics-challengekicks-off-in-dubai-1.67365555

Hamidi, C. (2018). Leading the Fourth Industrial Revolution: The UAE Case Study. Accessed October 24, 2019. Retrieved from: http://ed40.org/leading-the-fourthindustrial-revolution-the-uae-case-study/

Hansen, M., \& Gonzalez, T. (2014). Investigating the Relationship Between STEM Learning Principles and Student Achievement in Math and Science. American Journal of Education, 120(2), 139-171. doi:10.1086/674376

Hathcock, S. J., Dickerson, D. L., Eckhoff, A., \& Katsioloudis, P. (2015). Scaffolding for Creative Product Possibilities in Design-Based STEM Activity. Research in Science Education, 45(5), 727-748. doi:10.1007/s11165-014-9437-7

International Monetary Fund (IMF). (2014). Economic Diversification in the GCC: Past, Present, and Future. IMF Staff Discussion Note. doi:10.5089/9781498303231.006

Kamal, K. (2018). Education in the United Arab Emirates. Education System profiles. Accessed October 24, 2019. Retrieved from: https://wenr.wes.org/2018/08/education-in-the-united-arab-emirates

Kaul, M. (2016). How STEM Career Choices Set the UAE's Women Apart. Gulf News, Accessed October 24, 2019. Retrieved from: https://gulfnews.com/uae/education/how-stem-career-choices-set-the-uaeswomen-apart-1.1661603

Kennedy, T. J., \& Odell, M. R. L. (2014). Engaging Students in STEM education. Science Education International, 25(3), 246-258.

Laforce, M., Noble, E., \& Blackwell, C. (2017). Problem-Based Learning (PBL) and Student Interest in STEM Careers: The Roles of Motivation and Ability Beliefs. Education Sciences, 7(92), 1-22. doi:10.3390/educsci7040092

Lindeman, W. K., \& McKendry, E. (2015). Using Blocks to Develop 21st Century Skills. (Cover Story). YC: Young Children, 70(1), 36-43.

Maceda, C. (2017). UAE School Fees 'Second Highest in the World': HSBC Study. Gulf News, Accessed October 24, 2019. Retrieved from: https://gulfbusiness.com/uae-school-fees-second-highest-world-hsbc-study/

Makhmasi, S., Zaki, R., Barada, H., \& Al-Hammadi, Y. (2012). Students' Interest in STEM Education: A Survey From the UAE. doi:10.1109/educon.2012.6201144

Mcdonald, C. Y. (2016). STEM Education: A Review of the Contribution of the Disciplines of Science, Technology, Engineering and Mathematics. Science Education International, 27(4), 530-569. 
Mitts, C. (2016). Why STEM? Technology and Engineering Teacher, 75(6), 1-10.

Moonesar, I. A. (2015). Innovation in the UAE Public Sector. Innovation Days Series. Mohammed Bin Rashid School of Government and SAP.

Moye, J. J., Drugger, W. E., \& Starkweather, K. N. (2014). Is Learning by Doing Important. A Study of Doing-Based Learning. Technology and Engineering Teacher, 7(3), 22-28.

Park, H., Byun, S., Sim, J., Han, H., \& Baek, Y. S. (2016). Teachers' Perceptions and Practices of STEAM Education in South Korea. Eurasia Journal of Mathematics, Science and Technology Education, 12(7), 1739-1753. doi:10.12973/eurasia.2016.1531a

Pennington, R. (2017). UAE Parents Pay More Than Double Global Average for Education. The National UAE, July 2, 2017. Accessed October 24, 2019, Retrieved from: https://www.thenational.ae/uae/uae-parents-pay-more-than-doubleglobal-average-for-education-1.91253

Powell, W. W., \& Snellman, K. (2004). The Knowledge Economy. Annual Review of Sociology, 30, 199-220. doi:10.1146/annurev.soc.29.010202.100037

PWC (2019). Education Sector in UAE: Understanding Middle East Education. PWC Middle East. Retrieved From: https://www.pwc.com/ml/en/industries/education/education-countryprofile-united-arab-emirates.html

Radloff, J., \& Guzey, S. (2016). Investigating Preservice STEM Teacher Conceptions of STEM Education. Journal of Science Education and Technology, 25(5), 759-774. doi:10.1007/s10956-016-9633-5

Ritz, J., \& Fan, S. (2015). STEM and Technology Education: International State-of-the-Art. International Journal of Technology and Design Education, 25(4), 429-451. doi:10.1007/s10798-014-9290-z

Sengupta, C. (2019). Let's Talk About STEM. Gulf News Focus, Accessed October 24, 2019. Retrieved from: https://gulfnews.com/uae/education/lets-talk-aboutstem-1.1550478802548

Seymour, E. (2001). Tracking the Processes of Change in U.S. Undergraduate Education in Science, Mathematics, Engineering, and Technology. Science Education, 86(1), 79-105. doi:10.1002/sce.1044

Schiliro, D. (2013). Diversification and development of the UAE's Economy. Munich Personal RePEc Archive, Paper No. 47089.

Schultz, T.W. (1960). Capital Formation by Education. Journal of Political Economy, 68(6), 571-583. doi:10.1086/258393

Shaer, S., Zakzak, L., \& Shibl, E. (2019). The STEAM Dilemma: Advancing Sciences in UAE Schools: The Case of Dubai. A Report Published by Mohammed Bin Rashid School of Government (MBRSG). Retrieved from: https://www.mbrsg.ae/getattachment/174c88b2-e633-4dc9-9f9aa473f6c91892/The-STEAM-Dilemma-Advancing-Sciences-in-UAE-School.aspx

Shernoff, D., Sinha, S., Bressler, D., \& Ginsburg, L. (2017). Assessing Teacher Education and Professional Development Needs for the Implementation of Integrated Approaches to STEM Education. International Journal of STEM Education, 4(13), 116. doi:10.1186/s40594-017-0068-1

Shihab, M. (nd). Economic Development in the UAE. In: P. Hellyer and I. Al-Abed (Eds). The United Arab Emirates: A New Perspective. London: Trident Press Ltd.

Soomro, T. R. (2019). STEM education: United Emirates Perspective. Conference: the $20198^{\text {th }}$ International Conference. doi:10.1145/3318396.3318414

The Economist Intelligence Unit. (2014). UAE Economic Vision: Women in Science, Technology and Engineering. A Report from the Economist Intelligence Unit Limited. Retrieved from: https://www.eiuperspectives.economist.com 
The National. (2018). UAE Bucks Global Trend as Women Lead the Way in Science Studies. Updated, June 28, 2018. Retrieved from: https://www.thenational.ae/uae/uae-bucks-global-trend-as-women-lead-theway-in-science-studies-1.745043

UAE Government. (2017). UAE Strategy for Artificial Intelligence. Retrieved From: https://www.government.ae/en/about-the-uae/strategies-initiatives-andawards/federal-go...

U.S. Energy Information Administration. (2015). International Energy Data and Analysis: United Arab Emirates. May 18, 2015. Retrieved from: https://www.eia.gov

Varughese, K, J., \& Varughese, M. M. (2018). STEM: A Study in the Schools of Dubai, UAE. Proceedings of $8^{\text {th }}$ International Conference on Education and eLearning(Eel 2018), September 24-25, Singapore. Global Science and Technology Forum.

WAM, (2019). UAE Inaugurates Centre For Fourth Industrial Revolution. Gulf News, Accessed October 24, 2019. Retrieved from: https://gulfnews.com/uae/government/uae-inaugurates-centre-for-fourthindustrial-revolution-1.1556483000248

Wan-Husin, W., Mohamad Arsad, N., Othman, O., Halim, L., Rasul, M., Osman, K., \& Iksan, Z. (2016). Fostering students' 21 st_ Century Skills Through Project-Oriented Problem Based Learning (POPBL) in Integrated STEM Education Program. AsiaPacific Forum on Science Learning and Teaching, 17(1), 60-77.

White, D. W. (2014). What is STEM Education and Why is it Important? Florida Association of Teacher Educators Journal, 1(14), 1-9.

Winn, K., Choi, K., \& Hand, B. (2016). Cognitive Language and Content Standards: Language Inventory of the Common Core State Standards in Mathematics and the Next Generation Science Standards. International Journal of Education in Mathematics, Science and Technology, 4(4), 319-327. doi:10.18404/ijemst.26330

World Economic Forum. (2016). The Human Capital Report, 2016. Accessed October 24, 2019. Retrieved from https://www.weforum.org/reports/thehuman-capitalreport-2016

World Economic Forum (2018). The Future of Jobs: Employment, Skills and Workforce Strategy for the Fourth Industrial Revolution. Accessed October 24, 2019. Retrieved from: http://www3.weforum.org/docs/WEF_Future_of_Jobs.pdf

Xie, Y., Fang, M., \& Shauman, K. (2015). STEM Education. The Annual Review of Sociology, 41(19), 1-19. doi:10.1146/annurev-soc-071312-145659 